\title{
HUBUNGAN AKTIVITAS FISIK DENGAN TINGKAT STRES PADA PASIEN DIABETES MELITUS DI PUSKESMAS GONDOKUSUMAN 1 KOTA YOGYAKARTA
}

\author{
${ }^{1}$ Ni Made Winda Opelya, ${ }^{2}$ Adi Sucipto, ${ }^{3}$ Santi Damayanti, ${ }^{4}$ Siti Fadlilah \\ 1,2,3 Program Studi S-1 Ilmu Keperawatan Universitas Respati Yogyakarta, Indonesia \\ ${ }^{4}$ Program Pendidikan Profesi Ners, Universitas Respati Yogyakarta, Indonesia \\ Email: ${ }^{1}$ madewindaopelya98@gmail.com, ${ }^{2}$ adisucipto@respati.ac.id, ${ }^{3}$ santi.damaya@gmail.com, \\ ${ }^{4}$ sitifadlilah1010@gmail.com
}

\begin{abstract}
ABSTRAK
Stres merupakan salah satu kondisi yang rentan dirasakan oleh setiap pasien Diabetes Melitus (DM). Upaya penanganan stres pada pasien DM masih rendah, khususnya melalui pengelolaan aktivitas fisik. Pengelolaan aktivitas fisik harian sangat penting pada pasien DM, melalui aktivitas fisik dapat melepaskan energi dari otot skeletal sehingga bisa mengontrol gula darah tinggi yang dapat memicu stres pada pasien DM. Penelitian ini bertujuan untuk mengetahui hubungan antara aktivitas fisik dengan tingkat stres pada pasien DM. Jenis penelitian ini yakni kuantitatif menggunakan metode survei analitik dengan pendekatan secara retrospective. Jumlah sampel yang diteliti dari tanggal 13-27 Mei 2020 adalah 34 pasien DM. Pengambilan sampel menggunakan teknik accidental sampling dengan pengumpulan data dari google form melalui aplikasi whatsapp. Penelitian ini menggunakan International Physical Activity Questionnaires (IPAQ) dan Depression Anxiety Stress Scales (DASS). Analisis data menggunakan chi square. Hasil penelitian didapatkan sebagian besar responden kurang beraktivitas fisik yaitu 18 (52,9\%.) responden. Paling banyak responden mengalami stres, dan berada pada kategori stres sedang yaitu 12 (35,3\%) responden. Hasil uji statistik menggunakan chi square dengan nilai $\rho$ value 0,002 $(<0,05)$, sehingga disimpulkan ada hubungan antara aktivitas fisik dengan tingkat stres pada pasien DM di Puskesmas Gondokusuman 1 Kota Yogyakarta.
\end{abstract}

Kata Kunci :Aktivitas Fisik, Tingkat Stres, Diabetes Melitus.

\section{ABSTRACT}

Stress is a condition that is mostly felt by patients with diabetes mellitus. It is important to control stress level in patients with DM appropriately. One of them is managing daily physical activity in DM patients, through physical activity by releasing energy from skeletal muscle so that it can control high blood sugar which can cause stress in DM patients.To know the relationship of physical activity with stress level of DM patients 1, Yogyakarta City. This research is a kinf of quantitative research with analitic survey method and retrospective design. The sampling technique used was accidental sampling with 34 respondents from $13^{\text {th }}$ until $27^{\text {th }}$ on Mei and used google form on whatsapp application for data resume. The research instrument used was questionnaire of International Physical Activity Questionnaires (IPAQ) and Depression Anxiety Stress Scales (DASS). Analysis of research data used chi square. Most respondent in the category of lack physical activity that is $18(52,9 \%$.) respondent. The majority of respondent experienced stress, and have category of moderate stress that is $12(35,3 \%)$ respondent. Statistic test result using chi square with $\rho$ value $=0,002(<0,05)$. There is relationship between physical activity with stress level of DM patients in Puskesmas Gondokusuman 1 Yogyakarta City.

Keywords: Phsycal Activity, Stress Level, DM.

\section{PENDAHULUAN}

Diabetes Melitus (DM), merupakan kelompok penyakit metabolik yang ditandai dengan peningkatan kadar glukosa dalam darah akibat dari kekurangan sekresi insulin, gangguan aktivitas insulin, atau keduaduanya (Smeltzer \& Bare, 2010). Diabetes Melitus menjadi penyakit kronis yang disandang seumur hidup serta menimbulkan komplikasi yang akan berpengaruh pada ketidakstabilan ekonomi bagi pasien DM, sistem kesehatan dan ekonomi nasional, akibat dari biaya medis yang tinggi, kehilangan pekerjaan dan penghasilan pasien DM (Kemenkes RI, 2017). Kejadian DM mempengaruhi kualitas hidup serta perkembangan masalah kesehatan mental seperti stres karena tuntutan pentalaksanaan 
DM yang dilakukan seumur hidup (American Diabetes Association, 2018).

Berdasarkan estimasi (International Diabetes Federation, 2017) penduduk dunia yang mengalami DM diprediksi akan meningkat dari tahun 2017 sebanyak 425 juta jiwa sampai tahun 2045 sebanyak 629 juta jiwa dengan persentase kenaikan 48\%. Di dalam rentang waktu tersebut, DM tipe 2 menjadi tipe diabetes dengan prevalensi paling tinggi, terhitung sekitar $90 \%$ dari semua kasus diabetes. Di wilayah Western Pasific, IDF mengestimasikan peningkatan DM dari tahun 2017 sebanyak 159 juta jiwa sampai tahun 2045 sebanyak 183 juta jiwa dengan persentase kenaikan $15 \%$ yang dimana teritori ini mencakup 22 negara termasuk Indonesia.

Kejadian DM di Indonesia yang terdiagnosis oleh dokter menunjukan peningkatkan prevalensi DM di tingkat nasional dari $1.5 \%$ pada tahun 2013 , menjadi 2\% pada tahun 2018 (Rikesdas, 2018). DKI Jakarta menjadi provinsi yang menempati posisi tertinggi kejadian DM dengan prevalensi 2.6\% ditahun 2018. Daerah Istimewa Yogyakarta, prevalensi DM pada semua umur menempati posisi nomor dua di Indonesia dengan prevalensi $2.4 \%$ ditahun 2018. Kejadian DM di DIY tercatat mencapai 12.525 kasus di tahun 2018 dengan prevalensi kejadian DM tertinggi berada pada teritori perkotaan yakni mencapai $1.9 \%$ (Dinas Kesehatan D.I. Yogyakarta, 2018).

Meningkatnya kejadian DM membawa pengaruh peningkatan prevalensi kesehatan mental emosional seperti stres dari $6 \%$ di tahun 2013 menjadi $9.8 \%$ di tahun 2018 (Rikesdas, 2018). Ketika stres, tubuh akan merangsang saraf simpatik untuk menstimulasi kelenjar adrenal agar mensekresikan epinefrin sehingga hormon kortisol akan meningkat, hormon ini merespon dalam pengiriman glukosa ke dalam darah, hasilnya kadar gula darah akan lebih tinggi, selain itu hormon kortisol membuat pankreas sulit untuk mensekresikan insulin akibatnya pada pasien DM kadar gula darah menjadi tidak terkontrol (LeMone, Burke, \& Bauldoff, 2012).

Pasien DM dengan stres akan mempengaruhi nilai gula darah, gula darah yang semakin tinggi berdampak munculnya komplikasi, komplikasi ini semakin meningkatkan pengaruh pada kondisi fisik pasien DM, biaya perawatan dan penyedia pelayanan kesehatan, maka upaya untuk pengendalian stresor harus mampu dilakukan dengan baik upaya pengendalian tingkat stres pada pasien DM yang mempengaruhi gula darah dapat dilakukan dengan pengontrolan aktivitas fisik sehari-hari (Widodo, Tamtomo, $\&$ Prabandari, 2016).

Aktivitas fisik meliputi semua gerak tubuh yang ditimbulkan oleh otot-otot skeletal pada aktivitas sehari-hari. Aktivitas fisik pada pasien DM tidak dilakukan dengan intensitas berat seperti sehari-hari tidak sering mengangkat beban berat kemudian olahraga juga dianjurkan meliputi senam diabetik, yoga, hingga jalan kaki dalam intensitas ringan atau sedang yakni sekitar 15-30 menit dalam 1 hari. Aktivitas fisik tersebut jika dilakukan secara efisien dengan memperhatikan intensitasnya dapat mempengaruhi fisiologis tubuh melalui penghambatan produksi glukosa hati dan memicu penggunaan glukosa oleh otot, mekanisme tersebut dapat menekan produksi hormon adrenal dan merespon peningkatan hormon endorfin sehingga akan terjadi penurunan hormon kortisol yang membantu dalam mengurangi stres (Sarafino \& Smith, 2012).

Provinsi DIY dengan proporsi penduduk usia mulai $\geq 10$ tahun sesuai jenis aktivitas fisik menunjukkan Kota Yogyakarta memiliki proporsi terendah aktivitas fisik kategori aktif sebanyak $19.4 \%$ dan proporsi tertinggi aktivitas fisik kategori kurang aktif sebanyak 80.6\% (Rikesdas, 2013).

Berdasarkan hasil studi pendahuluan yang penulis lakukan pada tanggal 5 Februari 2020 didapatkan bahwa, jumlah pasien DM yang rutin melakukan pemeriksaan kesehatan setiap bulan sebanyak 70 pasien. Penulis melakukan studi pendahuluan terhadap 6 pasien DM terkait tingkat aktivitas fisik dan tingkat stres dengan kuesioner. Pada indikator tingkat aktivitas fisik didapatkan hasil 4 pasien dengan kategori kurang beraktivitas fisik yang meliputi 3 pasien dengan tingkat aktivitas fisik sedang serta 1 pasien dengan tingkat aktivitas fisik ringan (600-2900 METs), dan 2 pasien dengan kategori aktif beraktivitas fisik (>3000 METs). Sedangkan pada indikator tingkat stres, didapatkan hasil seluruh pasien 
mengalami stres meliputi 3 pasien dengan tingkat stres ringan, 2 pasien dengan tingkat stres sedang, dan 1 pasien dengan tingkat stres berat.

\section{METODE PENELITIAN}

Desain penelitian ini menggunakan survei analitik dengan teknik accidental sampling. Responden pada penelitian ini adalah anggota PROLANIS di Puskesmas Gondokusuman 1 Kota Yogyakarta sebanyak 34 responden yang memenuhi kriteria inklusi dan ekslusi yaitu:

a. Kriteria inklusi

1. Berpendidikan minimal SD

2. Usia 30-65 tahun

3. Aktif bergerak fisik

4. Mempunyai ponsel yang bisa digunakan untuk mengisi kuesioner.

b. Kriteria ekslusi

1. Responden yang mempunyai gangguan muskoloskeletal atau tidak dapat bergerak aktif secara fisik.

Responden yang bersedia dan memenuhi kriteria diberikan surat bersedia menjadi responden dan responden dikirimkan link google form melalui aplikasi whatsapp kemudian kuesioner diisi melalui form tersebut. Instrumen penelitian yang digunakan untuk aktivitas fisik yakni Physical Activity Questionnaires (IPAQ) dan untuk mengukur stres yakni Depression Anxiety Stress Scales (DASS).

Pengkategorian terkait karakteristik responden khususnya berdasarkan usia dikategorikan menjadi dewasa akhir 36-45, lansia awal 46-55, dan lansia akhir 56-65 (Depkes RI, 2009). Pada penelitian ini dalam mengukur aktivitas fisik dikategorikan menjadi aktif dan kurang aktif dengan memperhatikan skor pada kuesioner yakni aktif $\geq 3000$ METs dan kurang aktif <3000METs (Sadad, 2017; WHO, 2002). Pada pengukuran stres juga ditinjau dari skor kuesioner dengan nilai normal 0-14, rinngan 15-18, dan sedang 19-25 (Damanik, 2011; Lovibond, 1995).

Sebelum melakukan penelitian dilakukan uji etik untuk memastikan penelitian berjalan sesuai dengan etika penelitian di komisi etik UNRIYO pada tanggal 24 April 2020, dengan nomor surat etik 106.3/FIKES/PL/IV/2020. Pada hasil pengambilan data dilakukan pengolahan coding. editing, cleaning, dan tabulating kemudian analisis data menggunakan chi square. Pada penelitian ini hipotesis diterima apabila $\mathrm{p}$ value $<0,05$.

\section{HASIL DAN PEMBAHASAN}

3.1 Hasil

1. Analisis Univariat

a. Karakteristik Responden

Tabel 1. Distribusi Frekuensi Karakteristik Responden di Puskesmas Gondokusuman 1 Kota Yogyakarta, Bulan Mei $2020(\mathrm{n}=34)$

\begin{tabular}{|c|c|c|}
\hline Karakteristik & (f) & $(\%)$ \\
\hline \multicolumn{3}{|l|}{ Jenis Kelamin } \\
\hline Laki-laki & 16 & 47,1 \\
\hline Perempuan & 18 & 52,9 \\
\hline \multicolumn{3}{|l|}{ Usia } \\
\hline Dewasa akhir & 9 & 26,5 \\
\hline Lansia awal & 12 & 35,3 \\
\hline Lansia akhir & 13 & 38,2 \\
\hline \multicolumn{3}{|l|}{ Pendidikan } \\
\hline SD & 8 & 23,5 \\
\hline SLTP & 8 & 23,5 \\
\hline SLTA & 8 & 23,5 \\
\hline Sarjana & 10 & 29,5 \\
\hline \multicolumn{3}{|l|}{ Pekerjaan } \\
\hline PNS & 9 & 26,5 \\
\hline Pegawai Swasta & 9 & 26,5 \\
\hline Wiraswasta & 10 & 29,4 \\
\hline Petani & 6 & 17,6 \\
\hline \multicolumn{3}{|l|}{ Penghasilan } \\
\hline UMK & 18 & 52,9 \\
\hline$>$ UMK & 16 & 47,1 \\
\hline \multicolumn{3}{|l|}{ Lama DM } \\
\hline $1-10$ tahun & 22 & 64,7 \\
\hline$>10$ tahun & 12 & 35,3 \\
\hline \multicolumn{3}{|l|}{ Panyakit lain } \\
\hline Tidak ada & 8 & 23,5 \\
\hline Hipertensi & 17 & 50,0 \\
\hline Kolesterol & 9 & 26,5 \\
\hline \multicolumn{3}{|l|}{ Tipe DM } \\
\hline Tipe 1 & 8 & 23,5 \\
\hline Tipe 2 & 26 & 76,5 \\
\hline
\end{tabular}

Berdasarkan tabel 1, diketahui paling banyak responden lansia akhir berusia 56-65 tahun sebanyak 13 responden $(38,2 \%)$. Ditinjau dari jenis kelamin yakni sebagian besar perempuan sebanyak 18 responden $(52,9 \%)$. Melalui tingkat pendidikan didapat paling banyak sarjana sebanyak 10 responden $(29,4 \%)$. Melalui tingkat pekerjaan paling banyak memiliki pekerjaan sebagai 
wiraswasta yakni 10 responden $(29,4 \%)$. Penghasilan responden sebagian besar berada di bawah UMK adalah 18 responden $(52,9 \%)$. DM yang diderita sebagian besar kurang dari 10 tahun yakni 22 responden $(64,7 \%)$. Sebagian besar responden juga mengalami penyakit penyerta, sebagian besar mengalami hipertensi sebanyak 17 responden (50\%). Sebagian besar responden mengalami DM tipe 2 yakni 26 responden $(76,5 \%)$.

b. Nilai Aktivitas Fisik Responden

Tabel 2. Distribusi DataAktivitas Fisik

\begin{tabular}{lll}
\hline Aktivitas Fisik & (f) & $(\mathbf{\%})$ \\
\hline Kurang aktif & 18 & 52,9 \\
\hline Aktif & 16 & 47,1 \\
\hline Total & $\mathbf{3 4}$ & $\mathbf{1 0 0}$ \\
\hline
\end{tabular}

Sumber: Data primer
Berdasarkan tabel 2, diketahui dari 34 responden didapatkan sebagian besar responden kurang aktif beraktivitas fisik yakni sebanyak 18 responden $(52,9 \%)$.

\section{c. Nilai Tingkat Stres Responden}

Tabel 3. Distribusi Data Tingkat Stres

\begin{tabular}{|c|c|c|}
\hline Nilai Tingkat Stres & (f) & $(\%)$ \\
\hline Normal & 11 & 32,4 \\
\hline Ringan & 11 & 32,4 \\
\hline Sedang & 12 & 35,2 \\
\hline Total & 34 & 100 \\
\hline
\end{tabular}

Sumber: Data primer

Berdasarkan tabel 3, diketahui dari 34 responden didapatkan paling banyak mengalami stres tingkat sedang yakni 12 responden $(35,2 \%)$.

\section{Analisis Bivariat}

a. Karakteristik Responden dengan Aktivitas Fisik

Tabel 4. Distribusi Data Karakteristik Responden dengan Aktivitas Fisik (n=34) Karakteristik Responden Aktivitas Fisik

\begin{tabular}{lcccccc} 
& \multicolumn{2}{c}{ Kurang Aktif } & \multicolumn{2}{c}{ Aktif } & \multicolumn{2}{c}{ Total } \\
\hline & $\mathbf{f}$ & $\mathbf{( \% )}$ & $\mathbf{f}$ & $\mathbf{( \% )}$ & $\mathbf{f}$ & $\mathbf{( \% )}$ \\
\hline Usia & & & & & & \\
\hline Dewasa akhir & 3 & 33,3 & 6 & 66,7 & 9 & 100 \\
\hline Lansia awal & 7 & 58,3 & 5 & 41,7 & 12 & 100 \\
\hline Lansia akhir & 8 & 61,5 & 5 & 38,5 & 13 & 100 \\
\hline Pendidikan & & & & & & \\
\hline SD & 5 & 62,5 & 3 & 37,5 & 8 & 100 \\
\hline SLTP & 6 & 75,0 & 2 & 25,0 & 8 & 100 \\
\hline SLTA & 4 & 50,0 & 4 & 50,0 & 8 & 100 \\
\hline Sarjana & 3 & $(0,0$ & 7 & 70,0 & 10 & 100 \\
\hline Pekerjaan & & & & & & \\
\hline PNS & 3 & 33,3 & 6 & 66,7 & 9 & 100 \\
\hline Pegawai Swasta & 6 & 66,7 & 3 & 33,3 & 9 & 100 \\
\hline Wiraswasta & 5 & 50,0 & 5 & 50,0 & 10 & 100 \\
\hline Petani & 4 & 66,7 & 2 & 33,3 & 6 & 100 \\
\hline Penyakit Lain & & & & & & \\
\hline Tidak ada & 2 & 25,0 & 6 & 75,0 & 8 & 100 \\
\hline Hipertensi & 12 & 70,6 & 5 & 9,4 & 17 & 100 \\
\hline Kolesterol & 4 & 44,4 & 5 & 55,6 & 9 & 100 \\
\hline
\end{tabular}

Sumber: Data primer

Berdasarkan tabel 4, distribusi data berdasar usia dari 13 responden $(100 \%)$ yang berusia lansia akhir sebagian besar kurang beraktivitas fisik yaitu 8 responden $(61,5 \%)$, sedangkan paling banyak responden yang aktif beraktivitas fisik yaitu 5 responden $(38,5 \%)$. Berdasarkan pendidikan dari 10 responden (100\%) yang berpendidikan sarjana paling banyak kurang aktif berakitivitas fisik yaitu 3 responden $(30,0 \%)$, lalu sebagian besar responden aktif beraktivitas fisik yaitu 7 responden $(70,0 \%)$. Berdasarkan pekerjaan dari 10 responden (100\%) yang bekerja sebagai wiraswasta sebagian besar kurang aktif dan aktif berakitivitas fisik yaitu masing-masing 5 responden $(50,0 \%)$. Berdasarkan penyakit penyerta dari 17 responden (100\%) penyakit penyerta hipertensi sebagian besar kurang beraktivitas fisik yaitu 12 responden $(70,0 \%)$, sedangkan paling banyak aktif beraktivitas fisik yaitu 5 responden $(29,4 \%)$. 


\section{b. Karakteristik Responden dengan Tingkat Stres}

Tabel 5. Distribusi Data Karakteristik Responden dengan Tingkat Stres ( $n=34)$

\begin{tabular}{|c|c|c|c|c|c|c|c|c|}
\hline \multirow{3}{*}{$\begin{array}{c}\text { Karakteristik } \\
\text { Responden }\end{array}$} & \multicolumn{6}{|c|}{ Tingkat Stres } & \multirow{2}{*}{\multicolumn{2}{|c|}{ Total }} \\
\hline & \multicolumn{2}{|c|}{ Normal } & \multicolumn{2}{|c|}{ Ringan } & \multicolumn{2}{|c|}{ Sedang } & & \\
\hline & $\mathbf{f}$ & $(\%)$ & $\mathbf{f}$ & $\%$ & f & $(\%)$ & $\mathbf{f}$ & $(\%)$ \\
\hline \multicolumn{9}{|l|}{ Usia } \\
\hline Dewasa akhir & 4 & 44,4 & 4 & 44,4 & 1 & 11,2 & 9 & 100 \\
\hline Lansia awal & 3 & 25,0 & 5 & 41,7 & 4 & 33,3 & 12 & 100 \\
\hline Lansia akhir & 4 & 30,8 & 2 & 15,4 & 7 & 53,8 & 18 & 100 \\
\hline \multicolumn{9}{|l|}{ Jenis kelamin } \\
\hline Laki-laki & 6 & 37,5 & 4 & 25,0 & 6 & 37,5 & 19 & 100 \\
\hline Perempuan & 5 & 27,8 & 7 & 38,9 & 6 & 33,3 & 18 & 100 \\
\hline \multicolumn{9}{|l|}{ Pendidikan } \\
\hline $\mathrm{SD}$ & 4 & 50,0 & 2 & 25,0 & 2 & 25,0 & 8 & 100 \\
\hline SLTP & 1 & 12,5 & 3 & 37,5 & 4 & 50,0 & 8 & 100 \\
\hline SLTA & 3 & 37,5 & 1 & 12,5 & 4 & 50,0 & 8 & 100 \\
\hline Sarjana & 3 & 30,0 & 5 & 50,0 & 2 & 20,0 & 10 & 100 \\
\hline \multicolumn{9}{|l|}{ Pekerjaan } \\
\hline PNS & 2 & 22,2 & 5 & 55,6 & 2 & 22,2 & 9 & 100 \\
\hline Pegawai Swasta & 2 & 22,2 & 3 & 33,3 & 4 & 44,5 & 9 & 100 \\
\hline Wiraswasta & 5 & 50,0 & 1 & 10,0 & 4 & 40,0 & 10 & 100 \\
\hline Petani & 2 & 33,3 & 2 & 33,3 & 2 & 33,4 & 6 & 100 \\
\hline \multicolumn{9}{|l|}{ Penghasilan } \\
\hline <UMK & 6 & 33,3 & 5 & 27,8 & 7 & 38,9 & 18 & 100 \\
\hline >UMK & 5 & 31,3 & 6 & 37,5 & 5 & 31,2 & 16 & 100 \\
\hline \multicolumn{9}{|l|}{ Lama DM } \\
\hline 1-10 Tahun & 7 & 31,8 & 9 & 40,9 & 6 & 38,9 & 22 & 100 \\
\hline$>10$ Tahun & 4 & 33,3 & 2 & 16,7 & 6 & 31,2 & 12 & 100 \\
\hline \multicolumn{9}{|l|}{ Tipe DM } \\
\hline Tipe 1 & 3 & 37,5 & 9 & 25,0 & 3 & 37,5 & 8 & 100 \\
\hline Tipe 2 & 8 & 30,8 & 2 & 34,6 & 9 & 34,6 & 26 & 100 \\
\hline \multicolumn{9}{|l|}{ Penyakit Lain } \\
\hline Tidak ada & 2 & 25,0 & 5 & 62,5 & 1 & 12,5 & 8 & 100 \\
\hline Hipertensi & 5 & 29,4 & 5 & 29,4 & 7 & 41,2 & 17 & 100 \\
\hline Kolesterol & 4 & 44,4 & 1 & 11,2 & 4 & 44,4 & 9 & 100 \\
\hline
\end{tabular}

Berdasarkan tabel 5, distribusi data berdasar usia dari 18 responden yang berusia lansia akhir didapatkan sebagian besar tingkat stres sedang yaitu 7 responden $(53,8 \%)$. Berdasarkan jenis kelamin, dari 18 responden yang berjenis kelamin perempuan didapatkan paling banyak mengalami tingkat stres ringan yaitu 7 responden $(38,9 \%)$.

Berdasarkan tingkat pendidikan, dari 10 responden yang bekerja sebagai wiraswasta didapatkan sebagian besar tidak stres/normal yaitu 5 responden $(50,0 \%)$. Berdasarkan penghasilan, dari 18 responden yang berpenghasilan kurang dari UMK didapatkan paling banyak mengalami tingkat stres sedang yaitu 7 responden $(38,9 \%)$.
Berdasarkan lama DM, dari 22 responden yang mengalami lama DM 1-10 tahun didapatkan paling banyak mengalami tingkat stres ringan yaitu 9 responden $(40,9 \%)$. Berdasarkan tipe DM, dari 26 responden yang mengalami DM tipe 2 didapatkan paling banyak mengalami tingkat stres ringan dan tingkat stres sedang masingmasing yaitu 9 responden (34,6\%). Berdasarkan penyakit penyerta, dari 17 responden yang mempunyai penyakit penyerta hipertensi didapatkan paling banyak mengalami tingkat stres sedang yaitu 7 responden $(41,2 \%)$. 
c. Hubungan Aktivitas Fisik dengan Tingkat Stres Pada Pasien DM

Tabel 6. Hubungan Aktivitas Fisik dengan Tingkat Stres Pada Pasien DM

\begin{tabular}{|c|c|c|c|c|c|c|c|c|c|}
\hline \multirow{3}{*}{ Aktivitas Fisik } & \multicolumn{6}{|c|}{ Tingkat Stres } & \multirow{2}{*}{\multicolumn{2}{|c|}{ Total }} & \multirow[t]{3}{*}{ P value } \\
\hline & \multicolumn{2}{|c|}{ Normal } & \multicolumn{2}{|c|}{ Ringan } & \multicolumn{2}{|c|}{ Sedang } & & & \\
\hline & $\mathbf{f}$ & $\%$ & $\mathbf{f}$ & $\%$ & $\mathbf{f}$ & $\%$ & $\mathrm{f}$ & $\%$ & \\
\hline Kurang Aktivitas Fisik & 2 & 11,1 & 5 & 27,8 & 11 & 61,1 & 18 & 100 & \\
\hline Aktif Aktivitas Fisik & 9 & 56,3 & 6 & 37,5 & 1 & 6,2 & 16 & 100 & \\
\hline Total & 11 & 32,4 & 11 & 32,3 & 12 & 35,3 & 34 & 100 & 0.002 \\
\hline
\end{tabular}

Berdasarkan tabel 6, Hasil uji statistik menggunakan chi square diperoleh nilai $p=0.002 \quad(\rho$ value <0.05) maka dapat disimpulkan ada hubungan aktivitas fisik dengan tingkat stres pada pasien DM di Puskesmas Gondokusuman 1 Kota Yogyakarta.

\subsection{Pembahasan}

\section{Gambaran Aktivitas Fisik Pada Pasien DM}

Berdasarkan tabel 2, didapatkan bahwa pada aktivitas fisik sebagian besar termasuk dalam kurang beraktivitas fisik. Hasil penelitian tersebut sesuai seperti penelitian (Sadad, 2017), bahwa pasien DM umumnya kurang beraktivitas fisik yang dipengaruhi berbagai penyebab seperti kondisi kesehatan hingga pkisikis pada pasien DM. Seperti pada penelitian (Kurnianto, 2015), penderita DM banyak beraktivitas fisik yang kurang aktif, hal tersebut bisa disebabkan kurangnya pengetahuan tentang manfaat aktivitas fisik, seberapa banyak dan apa jenis aktivitas fisik yang harus dilakukan bahkan penderita DM sering tidak mengelola waktu untuk melakukan olahraga.

Data tersebut mendukung pada teori (Guyton, 2008), bahwa penderita DM lebih banyak istirahat dan kurang beraktivitas fisik, hal ini digunakan sebagai cara untuk menghambat terjadinya hipoglikemia yang bisa terjadi secara tiba-tiba. Seperti pada teori (Gibney et al, 2009), aktivitas fisik yang kurang aktif juga tidak dianjurkan pada pasien DM, sebab dapat mempengaruhi fisiologis tubuh yang meningkatkan terjadinya produksi glukosa oleh hati dan penggunaan glukosa oleh otot menjadi menurun, sehingga diabetisi juga berisiko mengalami kondisi gula darah yang tidak terkontrol.

Berdasarkan tabel 4, didapatkan bahwa sebagian besar lansia akhir yang kurang beraktivitas fisik yaitu 8 responden $(61,5 \%)$. Menurut teori (Hilliard et al, 2009), kurangnya aktivitas fisik pada pasien DM sering terjadi saat berusia lansia akhir akibat dari kualitas hidup pasien yang menurun. Hal tersebut tentunya akan menimbulkan berbagai permasalahan baik fisik hingga psikologis, meskipun demikian memanajemen kesehatan pasien DM melalui aktivitas fisik pada lanjut usia lebih juga dipengaruhi oleh berbagai penyebab salah satunya yakni penyakit lain yang diderita (Zainuddin, 2015).

Pada tabel 4, didapatkan sebagian besar responden yang berpendidikan sarjana yaitu 7 responden $(70,0 \%)$, termasuk dalam aktif beraktivitas fisik. Seperti penelitian (Abbasi, 2018), semakin tinggi pendidikan seseorang maka akan semakin mudah orang tersebut menerima informasi, sehingga umumnya memiliki pemahaman yang lebih baik dalam perawatan diri dalam peduli DM yang dialaminya. Meskipun demikian, tidak sepenuhnya berpendidikan tinggi menjamin seseorang dalam mengontrol kondisi kesehatannya.

Berdasarkan tabel 4, dari 10 responden yang bekerja sebagai wiraswasta/pedagang, didapatkan bahwa yang aktif beraktivitias fisik dengan kurang aktif beraktivitas fisik sebagian besar masing-masing yaitu 5 responden $(50,0 \%)$. Sejalan dengan penelitian (Tamara, 2014) pasien DM yang juga memiliki pekerjaan diluar rumah kemungkinan besar lebih aktif dalam beraktivitas fisik dibandingkan dengan pasien yang hanya sebagai ibu rumah tangga. Seperti teori (Black dan Hawks, 2005), pasien DM yang beraktivitas fisik baik yang mempunyai aktivitas di dalam atau di luar rumah tidak selalu menjadikan orang tersebut dalam kondisi yang aktif beraktivitas fisik, hal ini dikarenakan berbagai pemicu saat melakukan 
aktivitas seperti kesehatan, kondisi psikologis serta sosial.

Berdasarkan tabel 4, dari 17 responden yang mengalami hipertensi, didapatkan sebagian besar kurang beraktivitas fisik yaitu 12 responden $(70,6 \%)$. Data tersebut sesuai teori (Donald et al, 2013), penyakit penyerta atau komplikasi yang dialami pasien DM dapat mengakibatkan penurunan fungsi tubuh lainnya hingga dapat menghambat aktivitas fisik sehari-hari. Sejalan penelitian (Yusra, 2011), penyakit penyerta yang dialami pasien DM dapat mengakibatkan adanya keterbatasan saat beraktivitas fisik dan juga akan berdampak terhadap kualitas hidup. Dalam hal ini pasien DM di Puskesmas Gondokusuman 1 Kota Yogyakarta sebagian besar memiliki nilai aktivitas fisik yang kurang aktif. Pada pasien DM yang beraktivitas fisik kurang aktif butuh pengontrolan aktivitas fisik yang lebih baik, hal tersebut sangat penting bagi membantu mengurangi kecemasan dan dapat mengurangi stres (Sarafino \& Smith, 2012).

\section{Gambaran Tingkat Stres Pada Pasien DM}

Berdasarkan tabel 5, dari 18 responden yang berusia lansia akhir didapatkan sebagian besar mengalami tingkat stres sedang yaitu 7 responden $(53,8 \%)$. Data tersebut sesuai dengan teori, pasien DM yang lanjut usia mungkin sangat rentan terhadap stres dalam menghadapi perubahan kehidupan yang berhubungan dengan apa yang dahulu disebut sebagai tahun emas. Berbeda dengena penelitian (Nevid et al, 2005), mengasumsikan bahwa secara normal semakin bertambah usia sering terjadi penurunan atau perubahan dari segi fisik, intelektual, dan psikologis. Seperti penelitian (Retnowati, 2015), menyimpulkan hidup pasien DM lebih dipengaruhi oleh kondisi kronis seperti penyakit yang dialaminya daripada keadaan sosiodemografi (usia, jenis kelamin atau penghasilan).

Berdasarkan tabel 5, dari 18 responden yang berjenis kelamin perempuan paling banyak mengalami stres tingkat ringan yaitu 7 responden $(38,9 \%)$. Hal ini sesuai teori (Taylor, 2010), yang menyatakan bahwa penyebab utama banyaknya perempuan terkena diabetes karena terjadinya penurunan hormon estrogen terutama saat masa menopause. Berbeda dengan penelitian (Retnowati, 2015), yang menyatakan tidak ada hubungan antara jenis kelamin dengan stres pada hidup pasien DM. Hal yang memungkinkan berbeda dalam hal ini yakni responden yang sebagian besar adalah perempuan.

Berdasarkan tabel 5, dari 10 responden yang berpendidikan sarjana didapatkan sebagian besar mengalami stres tingkat ringan yaitu 5 responden $(50,0 \%)$. Sejalan penelitian (Widayati, 2017), memanajemen pendidikan tinggi yang didapat, bisa mempengaruhi pengontrolan stres pada pasien DM. Seperti penelitian (Kusnanto, 2019), tingkat pengetahuan melalui pendidikan tinggi yang didapat yakni bisa berpengaruh dengan terkontrolnya tingkat stres pasien kemudian sesuai teori (Abbasi et al, 2018), semakin tinggi tingkat pendidikan seseorang maka akan memiliki pemahaman yang baik tentang pentingnya perilaku perawatan diri dan memiliki keterampilan manajemen diri untuk kesehatan fisik maupun psikologis.

Berdasarkan tabel 5, dari 10 responden yang bekerja sebagai wiraswasta didapatkan sebagian besar tidak mengalami stres/normal yaitu 5 responden $(50,0 \%)$. Seperti penelitian (Gautam, 2009), pekerjaan belum tentu menyebabkan mengganggu kondisi psikologis seseorang melainkan sumber atau besarnya penghasilan lebih dapat membuat seseorang merasa khawatir/stres hingga tidak dapat memenuhi kebutuhannya.

Berdasarkan tabel 5, dari 18 responden yang berpenghasilan kurang dari UMK didapatkan paling banyak mengalami stres sedang yaitu 7 responden $(38,9 \%)$. Sejalan penelitian (Asfiana, 2015), bahwa memang benar penghasilan yang kurang dapat menyebabkan stres. Seperti teori (American Psychological Association, 2010), masalah keuangan dalam kehidupan sehari-hari ternyata merupakan salah satu stresor utama bagi seseorang. Namun meskipun demikian, penghasilan sesorang yang kurang dari UMK mungkin juga mempunyai pengeluaran yang sedikit, sehingga tidak berpengaruh signifikan dengan kondisi psikologis pasien DM.

Berdasarkan tabel 5, dari 22 responden yang mempunyai DM selama durasi 1-10 tahun didapatkan paling banyak mengalami 
stres tingkat ringan yaitu 9 responden $(40,9 \%)$. Sejalan penelitian (Ningtyas, 2013), yang menyatakan bahwa ada hubungan yang signifikan lama DM dengan kondisi psikologis pasien DM yakni dengan memperhatihan dari segi efikasi diri yang lebih baik. Berbeda dalam teori (Donald et al, 2013), bahwa lama menderita DM tidak berpengaruh langsung dengan kondisi psikologis pasien DM, hal itu umumnya disebabkan oleh kondisi fisik selama menderita DM seperti adanya komplikasi yang mempengaruhi stres pasien DM.

Berdasarkan tabel 5, dari 26 responden yang mempunyai DM tipe 2 didapatkan paling banyak mengalami stres ringan dan stres sedang masing-masing yaitu 9 responden $(34,6 \%)$. Sejalan dengan teori (Smeltzer dan Bare, 2010), mayoritas penderita DM tipe 2 paling berisiko mengalami masalah psikologis, karena memanjemen retensi insulin pada DM tipe 2 akan semakin meningkat di samping terdapat riwayat keturunan dan obesitas. Seperti penelitian (Izzati, 2015), pasien dengan DM tipe 2 mempunyai risiko psikologis yang kurang baik disebabkan karena keharusan untuk mengontrol perihal suplai insulin hingga pola makan yang diterapkan seharihari.

Berdasarkan tabel 5, dari 17 responden yang mempunyai penyakit penyerta berupa hipertensi didapatkan paling banyak mengalami tingkat stres sedang yaitu 7 responden (41,2\%). Menurut teori (Damayanti, 2015), patogenesis hipertensi pada penderita DM sangat kompleks, banyak faktor yang berpengaruh pada peningkatan tekanan darah misalnya resistensi insulin, obesitas hingga kadar gula darah plasma. Meskipun demikian, hidup dengan diabetes tanpa atau dengan komplikasi tetap mempunyai pengaruh yang negatif terhadap kondisi psikologis pasien DM (Zainuddin, 2015).

\section{Hubungan Aktivitas Fisik dengan Tingkat Stres Pada Pasien DM}

Berdasarkan tabel 6 , didapatkan $\mathrm{p}$ value $=0.002(\mathrm{p}$ value $<0,05)$ sehingga hipotesis diterima, artinya ada hubungan yang signifikan antara aktivitas fisik dengan tingkat stres pada pasien DM. Hal ini dapat diartikan bahwa aktivitas fisik mempunyai kontribusi dan pengaruh signifikan pada tingkat stres yang dialami pasien DM.

Pada penelitian ini, didapatkan 18 responden $(100 \%)$, memiliki aktivitas fisik yang kurang aktif dengan paling banyak tidak stres/normal yaitu 2 responden $(11,1 \%)$, paling banyak stres tingkat ringan yaitu 5 responden $(27,8 \%)$, dan sebagian besar mengalami stres tingkat sedang yaitu 11 responden $(61,1 \%)$. Sejalan dengan teori (Sarafino \& Smith, 2012), aktivitas fisik yang kurang aktif berpengaruh meningkatkan produksi glukosa hati dan penurunan penggunaan energi oleh otot sehingga terjadi peningkatan hormon kortisol dan munculnya stres. Seperti penelitian (Widodo et al, 2016), tingginya tingkat stres sejalan dengan ditandai tingginya gula darah yang bisa diakibatkan akibat kurang beraktivitas fisik.

Sesuai dengan teori (Haskell et al, 2007), aktivitas fisik mempengaruhi kondisi stres pada pasien DM, aktivitas fisik yang kurang dapat menyebabkan meningkatknya glukosa dalam darah. Sejalan dengan penelitian (Dolongseda et al, 2017), aktivitas fisik yang aktif akan mempengaruhi proses metabolisme glukosa sehingga dapat mengontrol gula darah yang dimana gula darah tinggi dapat menyebabkan munculnya risiko stres pada pasien DM. Diperkuat juga melalui penelitian (Widodo et al, 2016), tingginya tingkat stres sejalan dengan ditandai tingginya gula darah yang bisa diakibatkan akibat kurang beraktivitas fisik.

Hasil penelitian juga didapatkan 2 responden $(11,1 \%)$ yang kurang aktif beraktivitas fisik tetapi tidak mengalami stres/normal. Berbeda dengan teori (Gibney, 2009), pasien DM yang melakukan aktivitas fisik secara aktif akan terhindar dari stres akibat metabolisme glukosa dalam tubuh melalui pergerakan otot skeletal. Meskipun demikian aktivitas fisik yang kurang aktif tidak selalu menjamin dapat mengontrol stres khususnya pada pasien DM.

Menurut asumsi peneliti, stres pada pasien DM tidak hanya dipicu melalui seberapa aktivitas yang dilakukan sehari-hari namun banyak penyebab lainnya yang ikut memicu terjadinya stres, seperti pada penelitian ini terdapat beberapa variabel perancu yang tidak peneliti kendalikan bahkan dapat mempengaruhi stres pada 
pasien DM seperti genetik, persepsi, motivasi, status sosial, dan lingkungan sosial.

Melalui salah satu variabel perancu yaitu motivasi, pasien DM yang mempunyai motivasi supportif akan dapat memanajamen kesehatannya menjadi lebih baik dan begitu juga sebaliknya. Sejalan dengan penelitian (Herdianti et al, 2017), pasien DM yang tidak mempunyai motivasi dalam memanajemen kesehatannya akan berisiko 5,14 kali mengalami stres. Sesuai teori (Lazarus dan Folkman, 2010), motivasi dapat bertindak sebagai buffer terhadap stres dan akibatnya membantu mencegah stres pada pasien DM., semakin tinggi motivasi dalam memanajemen kesehatan semakin rendah stres pada pasien DM.

Pemicu lain yang dapat menyebabkan stres yaitu status sosial pada pasien DM. Seperti penelitian (Murante et al, 2018), lingkungan dan status sosial yang mendukung kesehatan pasien DM akan menurunkan tingkat stres yang dialami. Sesuai dengan teori (Taylor et al, 2009),bahwa lingkungan sosial yang bersifat supportif dapat meredam efek stres, membantu individu mengatasi stres dan mendapatkan kesehatan yang lebih baik.

Pada penelitian ini juga terdapat variabel lainnya yang dapat memicu stres pada pasien DM yaitu melalui genetik/keturunan hingga persepsi kesehatan. Menurut teori (Yusuf, Fitryasari, \& Nihayati, 2015), seseorang yang mengalami gangguan pada kesehatan melalui keturunan akan rentan terkena berbagai penyakit, gangguan pada fisik, dan psikis. Hal tersebut yang ikut andil dalam pemicu stres pasien DM bahkan selain munculnya stres, melalui genetik juga berpengaruh pada kualitas hidup pasien DM.

\section{KESIMPULAN}

1. Responden di Puskesmas Gondokusuman 1 Kota Yogyakarta sebagian besar berusia lansia akhir, berjenis kelamin perempuan, berpendidikan sarjana, bekerja sebagai wiraswasta, berpenghasilan <UMK, lama DM <10 tahun, penyakit penyerta dengan hipertensi, dan sebagian besar DM tipe 2 .

2. Aktivitas fisik pasien DM di Puskesmas Gondokusuman 1 Kota Yogyakarta sebagian besar masuk dalam kategori kurang aktif.
3. Tingkat stres pasien DM di Puskesmas Gondokusuman 1 Kota Yogyakarta paling banyak masuk dalam tingkat stres sedang.

4. Ada hubungan antara aktivitas fisik dengan tingkat stres pada pasien DM di Puskesmas Gondokusuman 1 Kota Yogyakarta.

\section{REFERENCES}

Abbasi Yap Cheng Hoon 4 SP (2018). Diabetes Knowledge, Attitude, Practice Among Type 2 Diabetes Mellitus Malaysia. Sectional Study.

American Diabetes Asociation (2018). Updates to the Standards of Medical Care in Diabetes.

Asfiana, N. W (2015). Hubungan Tingkat Penghasilan Dengan Tingkat Stres Kepala Keluarga Penduduk Dukuh Klile. Fakultas Kedokteran Universitas Muhammadiyah Surakarta 2015.

Black, J. M., \& Hawks, J. H (2005). Medical surgical nursing: Clinical Managemen for positive outcomes. (7th). Elsevier.

Damayanti, S. (2015). Manajemen Diabetes Mellitus. Yogyakarta: Nuha Medika.

Dolongseda, Masi, \& Bataha, 2017. (2017). Hubungan Pola Aktivitas Fisik Dan Pola Makan Dengan Kadar Gula Darah Pada Pasien Diabetes Melitus Tipe II Di Poli Penyakit Dalam Rumah Sakit Pancaran Kasih Gmim Manado. Jurnal Keperawatan, 5(1).

Donald, M., Dower, J., Coll, J.R (2013). Mental health issues decrease diabetesspecific quality of life and complications: fi ndings from Australia's living with diabetes cohort study.

Gautam, Y., Sharma. (2009). A Cross Sectional Study of QOL of diabetic patient at tertiary care hospital in Delhi. Indian Journal of Community Medicine. (n.d.).

Gibney. (2009). Gizi Kesehatan Masyarakat. Jakarta: EGC.

Guyton. (2008). Buku Ajar Fisiologi Kedokteran. Jakarta: EGC.

Haskell, W. L., Lee, I. M., Pate, R. R., Powell. (2007). Physical activity and public health: Updated recommendation for adults from the American College of Sports Medicine and the American Heart Association.

Herdianti. (2017). Kualitas hidup 
mempengaruhi kesehatan fisik. 2 (February), 74-80. Program Studi Kesehatan Masyarakat STIKES Harapan Ibu Jambi.

Hilliard, Marisa E. et al. (2009). Predictors Of Diabetes-Related Quality Of Life After Transitioning To The Insulin Pump. Pediatric Psychology 34.

International Diabetes Federation. (2017). Diabetes Atlas. In IDF Diabetes Atlas (8th editio). https://doi.org/http://dx.doi. org/10.1016/S0140-6736(16)31679-8.

Izzati, W., \& Nirmala. (2015). Kadar Gula Darah Pada Pasien Diabetes Mellitus Di Wilayah Kerja Puskesmas Perkotaan Rasimah Ahmad Bukit Tinggi Tahun 2015. Keperawatan.

Kementerian Kesehatan RI. Badan Penelitian dan Pengembangan. (2013). Hasil Utama Riset Kesehatan Dasar. Kementrian Kesehatan RI.

Kementerian Kesehatan RI. Badan Penelitian dan Pengembangan. (2018). Hasil Utama Riset Kesehatan Dasar. Kementrian Kesehatan RI.

Murante, A.M (2018). The diabetes selfmanagement educational programs and their integration in the usual care: Health Policy, 122 (8), 866-877.

Kurnianto, DP. (2015). Menjaga Kesehatan di Usia Lanjut. Prodi Ilmu Keolahragaan PPS UNY, 11(2) : 19-29. (n.d.). No Title.

Kusnanto, K., Sundari, P. M., Asmoro, C. P., \& Arifin, H. (2019). Hubungan Tingkat Pengetahuan Dan Diabetes SelfManagement Dengan Tingkat Stres Pasien Diabetes Melitus. Jurnal Keperawatan Indonesia.

Lazarus, F. (2010). Stress Appraisal and Coping. In Springer Publishing Company New York.

Nevid, Jeffrey S. (2005). Psikologi Abnormal edisi kelimaJilid 1. Jakarta: Erlangga.

Ningtyas, D. W., Wahyudi, dr. P., \& Prasetyowati, I. (2013). Analisis Kualitas Hidup Pasien Diabetes Melitus Tipe 2 di RSUD Bangil Kabupaten Pasuruan. Artikel Ilmiah Hasil Penelitian Mahasiswa.

Notoatmodjo, S. (2007). Promosi Kesehatan \& Ilmu Perilaku. Jakarta: Rineka Cipta.

Priscilla LeMone, Karen M.Burke, \& G. B
(2012). Buku Ajar Keperawatan Medikal Bedah. Jakarta: EGC.

Retnowati, N., \& Satyabakti, P. (2014). Hidup Penderita Diabetes Melitus Di Puskesmas Tanah. 3, 57-68.

Sadad, P. (2017). Hubungan aktivitas fisik dengan kejadian diabetes melitus tipe II di rsud kota yogyakarta, daerah istimewa yogyakarta. Universitas Respati Yogyakarta.

Sarafino \& Smith. (2012). Health Phsycology. United States Of America.

Smeltzer S.C, Bare B.G, Hinkle J.L, C. K. . (2010). Medical Surgical Nursing (12th ed.). Philadelphia: Lippincott Williams \& Wilkins.

Tamara, E., \& Nauli, F. A. (2014). Hubungan atara dukungan keluarga dan kualitas Hidup Pasien Diabetes Mellitus Tipe II Di Rsud Arifin Achmad Provinsi Riau.

Taylor, C., Lillis, C., Lemone, P., \& Lynn, P. (2010). Fundamental of nursing: The Art and Scienceof Nursing Care (7th). Philadelphia: LippincottWilliams \& Wilkins.(n.d.).

Wiastuti, S. M., Rondhianto, R., \& Widayati, N (2017). Pengaruh DSME Pada Pasien Diabetes Melitus (DM) Tipe 2 Di Wilayah Kerja Puskesmas Patrang Kabupaten Jember. Pustaka Kesehatan, 5(2), 268-275

Widodo, C., Tamtomo, D., \& Prabandari, A. N (2016). Hubungan Aktifitas Fisik, Kepatuhan Mengkonsumsi Obat Anti Diabetik Dengan Kadar Gula Darah. Jurnal Sistem Kesehatan, 2(2), 63-69.

Yusra, A. (2011). Hubungan antara dukungan keluarga dengan kualitas hidup pasien diabetes mellitus tipe 2 di poliklinik penyakit dalam rumah sakit umum pusat fatmawati Jakarta. Tesis, 1-137.

Yusuf. (2015). Keperawatan Kesehatan Jiwa. In Buku Ajar Keperawatan Kesehatan Jiwa.

Zainuddin, M., Utomo, W., \& Herlina. (2015). Hubungan Stres dengan Kualitas Hidup Penderita Diabetes Mellitus Tipe 2. Jurnal Online Mahasiswa Program Studi Ilmu Keperawatan Universitas Riau, 2(1), 890-898. 